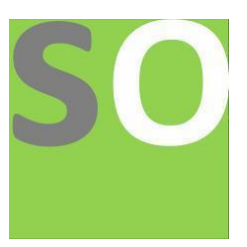

Article title: Portable Gantry Crane Payload Angle Limitation Control with the Presence of Trolley Position Vibration using Optimal Control

Authors: Mustefa Jibril[1], Messay Tadese[2], Reta Degefa[3]

Affiliations: School of Electrical and Computer Engineering[1]

Orcid ids: 0000-0002-3165-2410[1]

Contact e-mail: mustefazinet1981@gmail.com

License information: This work has been published open access under Creative Commons Attribution License http://creativecommons.org/licenses/by/4.0/, which permits unrestricted use, distribution, and reproduction in any medium, provided the original work is properly cited. Conditions, terms of use and publishing policy can be found at https://www.scienceopen.com/.

Preprint statement: This article is a preprint and has not been peer-reviewed, under consideration and submitted to ScienceOpen Preprints for open peer review.

DOI: 10.14293/S2199-1006.1.SOR-.PPR2TL7.v1

Preprint first posted online: 15 September 2020

Keywords: Portable gantry crane, $\mathrm{H} 2$ synthesis controller, $\mathrm{Mu}$ - synthesis controller 


\title{
Portable Gantry Crane Payload Angle Limitation Control with the Presence of Trolley Position Vibration using Optimal Control
}

\author{
Mustefa Jibril ${ }^{1}$, Messay Tadese ${ }^{2}$, Reta Degefa ${ }^{3}$ \\ ${ }^{1}$ Msc, School of Electrical \& Computer Engineering, Dire Dawa Institute of Technology, Dire Dawa, \\ Ethiopia \\ ${ }^{2}$ Msc, School of Electrical \& Computer Engineering, Dire Dawa Institute of Technology, Dire Dawa, \\ Ethiopia \\ ${ }^{3}$ Msc, School of Electrical \& Computer Engineering, Dire Dawa Institute of Technology, Dire Dawa, \\ Ethiopia \\ mustefa.jibril@ddu.edu.et
}

\begin{abstract}
In this paper, a portable gantry crane is designed and controlled with the presence of trolley vibration disturbance using robust control technique. In the open loop system, the payload angle is not stable in both the impulse and step input force signals. Comparison of the system with $\mathrm{H} 2$ and $\mu$ - synthesis controllers have been done for a step and impulse input force signal and a promising results have been analyzed.
\end{abstract}

Keywords: Portable gantry crane, H 2 synthesis controller, $\mu$ - synthesis controller

\section{Introduction}

Portable gantry cranes are used to lift and move smaller items, usually less than 5 tons. They are widely used in vehicle motor installation, machinery installation in industries. Some portable gantry cranes are equipped with a trolley moving track, while others utility an I-beam, or other extruded shapes, for the movable surface. Most portable gantry cranes are intended to be stationary when loaded, and mobile when unloaded. Portable Gantry Cranes can be outfitted with either a cord rope hoist or a lower capacity chain hoist.

\section{Mathematical Modeling of Portable Gantry Crane}

The portable gantry crane with trolley vibration disturbance model is shown in Figure 1 below.

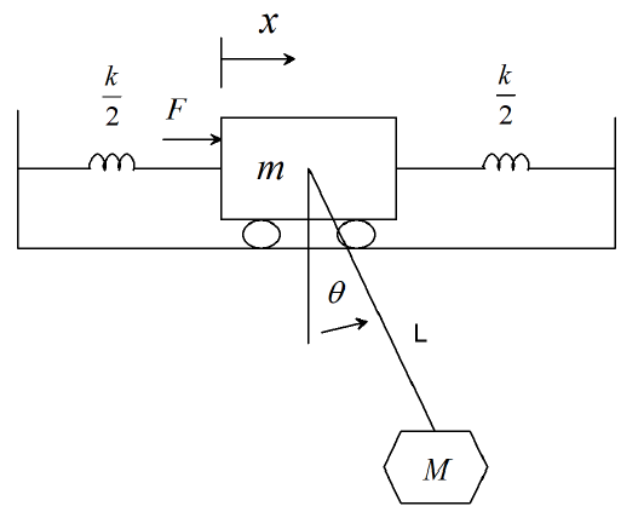

Figure 1 Portable gantry crane with trolley vibration disturbance model 
The differential equation describing the motion of the crane is:

$$
\begin{gathered}
(M+m) \ddot{x}+K x+M L \ddot{\theta} \cos \theta-M L \dot{\theta}^{2} \sin \theta=F \\
L \ddot{\theta}+\ddot{x} \cos \theta+g \sin \theta=0
\end{gathered}
$$

Assuming $\theta$ is small angle Equation (1) and (2) becomes

$$
\begin{gathered}
(M+m) \ddot{x}+K x+M L \ddot{\theta}=F \\
L \ddot{\theta}+\ddot{x}+g \theta=0
\end{gathered}
$$

Let

$$
x_{1}=x, x_{2}=\dot{x}, x_{3}=\theta, x_{4}=\dot{\theta} \text { and } u=F
$$

So the state space representation becomes:

$$
\begin{aligned}
& {\left[\begin{array}{l}
\dot{x}_{1} \\
\dot{x}_{1} \\
\dot{x}_{1} \\
\dot{x}_{1}
\end{array}\right]=\left(\begin{array}{cccc}
0 & 1 & 0 & 0 \\
-\frac{K}{m} & 0 & \frac{M}{m} g & 0 \\
0 & 0 & 0 & 1 \\
\frac{K}{m L} & 0 & -\frac{(M+m)}{m L} g & 0
\end{array}\right)\left[\begin{array}{l}
x_{1} \\
x_{2} \\
x_{3} \\
x_{4}
\end{array}\right]+\left[\begin{array}{l}
0 \\
\frac{1}{m} \\
0 \\
-\frac{1}{m L}
\end{array}\right] u} \\
& y=\left(\begin{array}{llll}
1 & 0 & 0 & 0 \\
0 & 0 & 1 & 0
\end{array}\right)\left[\begin{array}{l}
x_{1} \\
x_{2} \\
x_{3} \\
x_{4}
\end{array}\right]
\end{aligned}
$$

The parameter of the portable gantry crane is shown in Table 1 below

Table 1 Parameters

\begin{tabular}{|l|l|l|l|}
\hline No & Parameter & Symbol & Value \\
\hline 1 & Trolley mass & $m$ & $120 \mathrm{Kg}$ \\
\hline 2 & Payload mass & $M$ & $1200 \mathrm{Kg}$ \\
\hline 3 & Spring stiffness & $K$ & $8 \mathrm{~N} / \mathrm{m}$ \\
\hline 4 & Rod Length & $L$ & $2 \mathrm{~m}$ \\
\hline 5 & Gravity constant & $g$ & $9.8 \mathrm{~m} / \mathrm{s}^{2}$ \\
\hline
\end{tabular}

The portable gantry crane state space description is shown below 


$$
\begin{aligned}
& {\left[\begin{array}{l}
\dot{x}_{1} \\
\dot{x}_{1} \\
\dot{x}_{1} \\
\dot{x}_{1}
\end{array}\right]=\left(\begin{array}{cccc}
0 & 1 & 0 & 0 \\
-0.006 & 0 & 98 & 0 \\
0 & 0 & 0 & 1 \\
0.033 & 0 & -54 & 0
\end{array}\right)\left[\begin{array}{l}
x_{1} \\
x_{2} \\
x_{3} \\
x_{4}
\end{array}\right]+\left[\begin{array}{l}
0 \\
0.8 \\
0 \\
-0.4
\end{array}\right] u \times 10^{2}} \\
& y=\left(\begin{array}{llll}
1 & 0 & 0 & 0 \\
0 & 0 & 1 & 0
\end{array}\right)\left[\begin{array}{l}
x_{1} \\
x_{2} \\
x_{3} \\
x_{4}
\end{array}\right]
\end{aligned}
$$

\section{The Proposed Controller Design}

The design of portable gantry crane system to provide payload control is evolved the use of $\mathrm{H} 2$ and $\mu$ - synthesis controllers design. In the portable gantry crane system, the proposed controllers design to control the payload angle and to analyze the effect of trolley vibration on the payload angle. The predominant purpose of the controller design is to decrease the payload angle even with the presence of trolley vibration. Synthesis method is used to design the proposed controllers through reaching the overall performance objective through minimizing the payload angle. The portable gantry crane system with $\mathrm{H} 2$ and $\mu$ - synthesis controller's system interconnections block is shown in Figure 2 below.

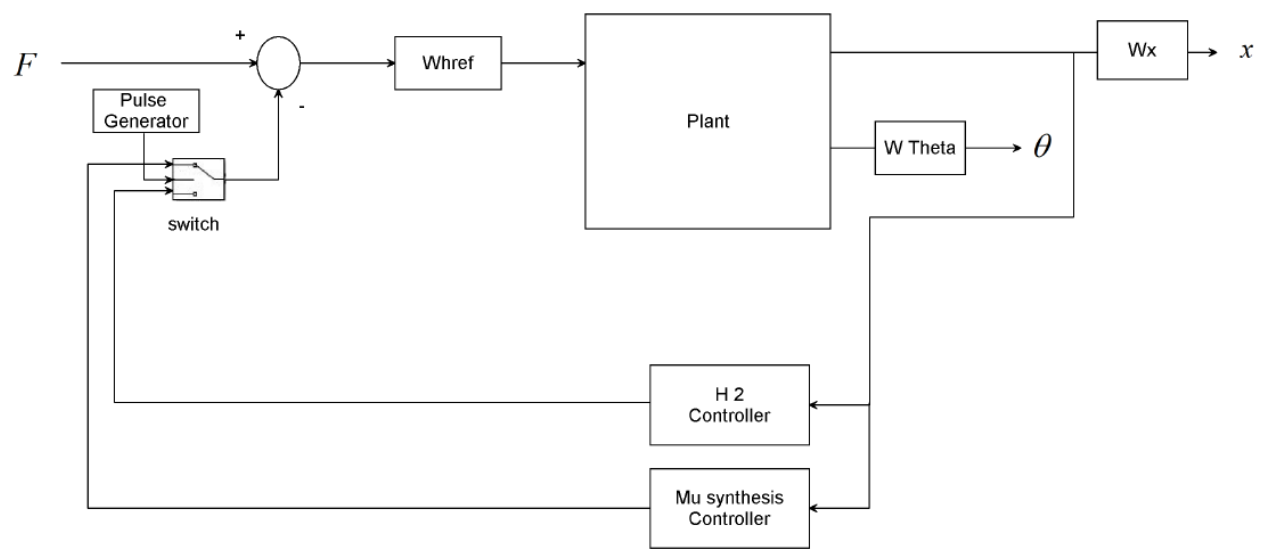

Figure 2: Portable gantry crane system with $\mathrm{H} 2$ and $\mu$ - synthesis controller's system interconnections block diagram

A $\mu$-synthesis controller is synthesized with the usage of $\mathrm{D}-\mathrm{K}$ iteration. The $\mathrm{D}-\mathrm{K}$ iteration method is an approximation to synthesis that tries to synthesize the controller. There is one manipulate input the desired payload angle.

The controller's acts on the y signal to produce the feedback trolley position signal. The Wx block modelled the disturbance inside the channel. Wx is given a disturbance noise of $0.09 \mathrm{~m}$.

$$
W_{x}=0.09
$$


The magnitude of the force disturbance is scaled using the weight Whref. Let us assume the maximum force disturbance is $0.2 \mathrm{~N}$ which means

$$
W_{\text {href }}=0.2
$$

\section{Result and Discussion}

\subsection{Portable Gantry Crane Open Loop Impulse Response}

The open loop impulse response of the trolley position and payload angle for a $100 \mathrm{~N}$ input is shown in Figure 3 and Figure 4 respectively.

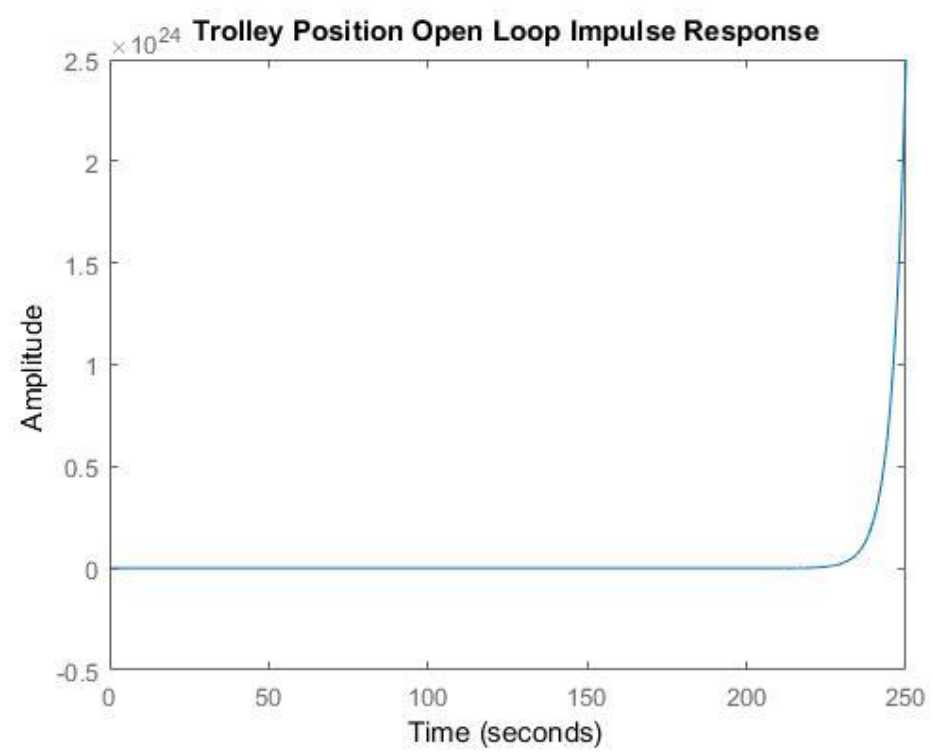

Figure 3 Trolley open loop impulse response

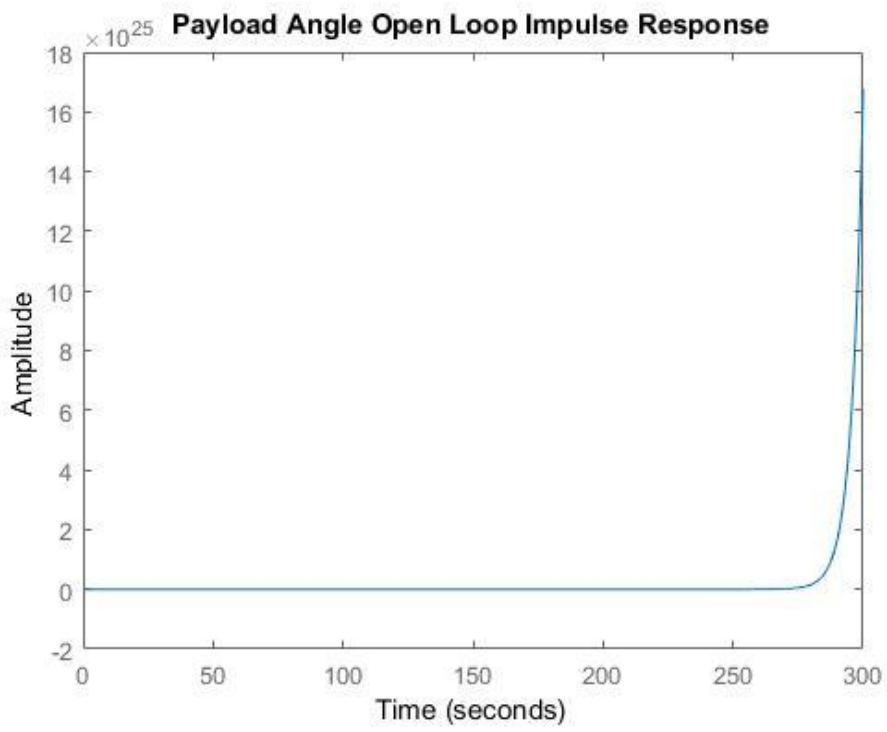

Figure 4 Payload open loop impulse response 
The impulse response simulation results show that both the trolley position and the payload angle are not stable.

\subsection{Portable Gantry Crane Open Loop Step Response}

The open loop step response of the trolley position and payload angle for a $100 \mathrm{~N}$ input is shown in Figure 5 and Figure 6 respectively.

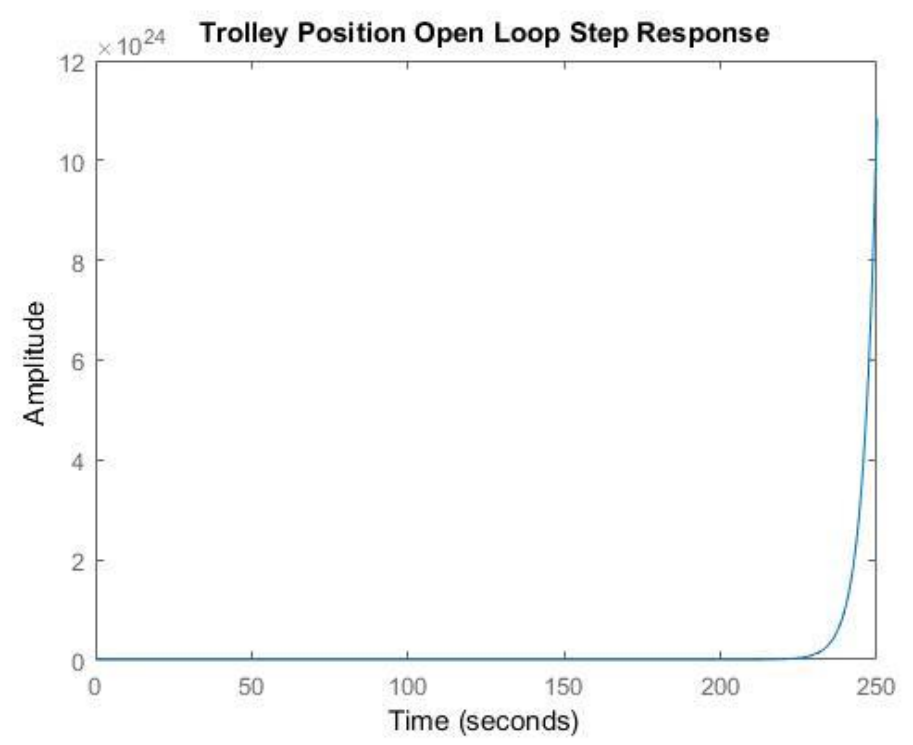

Figure 5 Trolley open loop step response

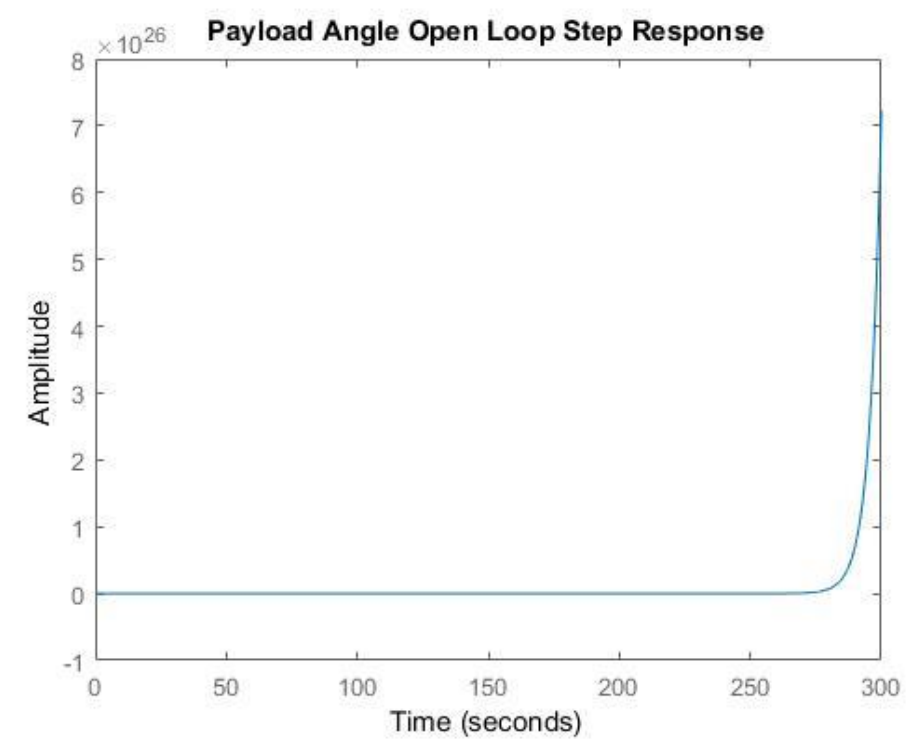

Figure 6 Payload open loop step response

The open loop step response simulation results show that both the trolley position and the payload angle are not stable. 


\subsection{Comparison of the Portable Gantry Crane with the Proposed Controllers for an Impulse Force Signal}

The comparison simulation result of the impulse response of the trolley position and payload angle for a $100 \mathrm{~N}$ input force are shown in Figure 7 and Figure 8 respectively.

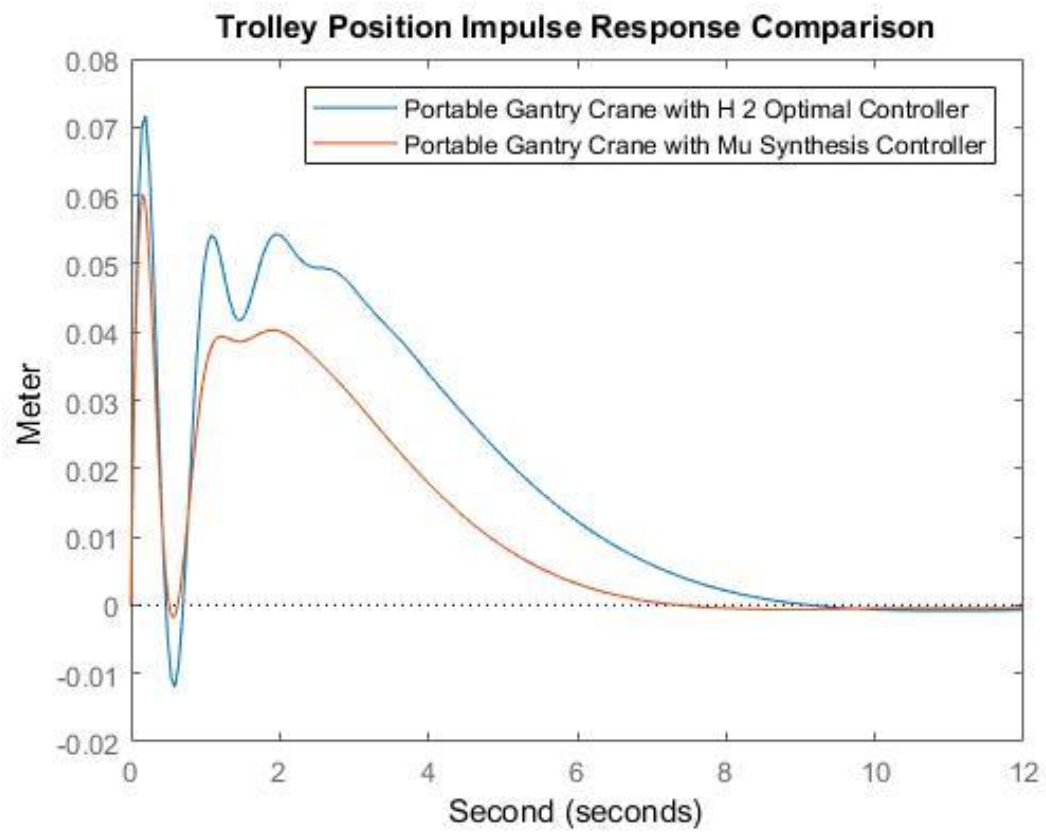

Figure 7 Comparison simulation result of the impulse response of the trolley position

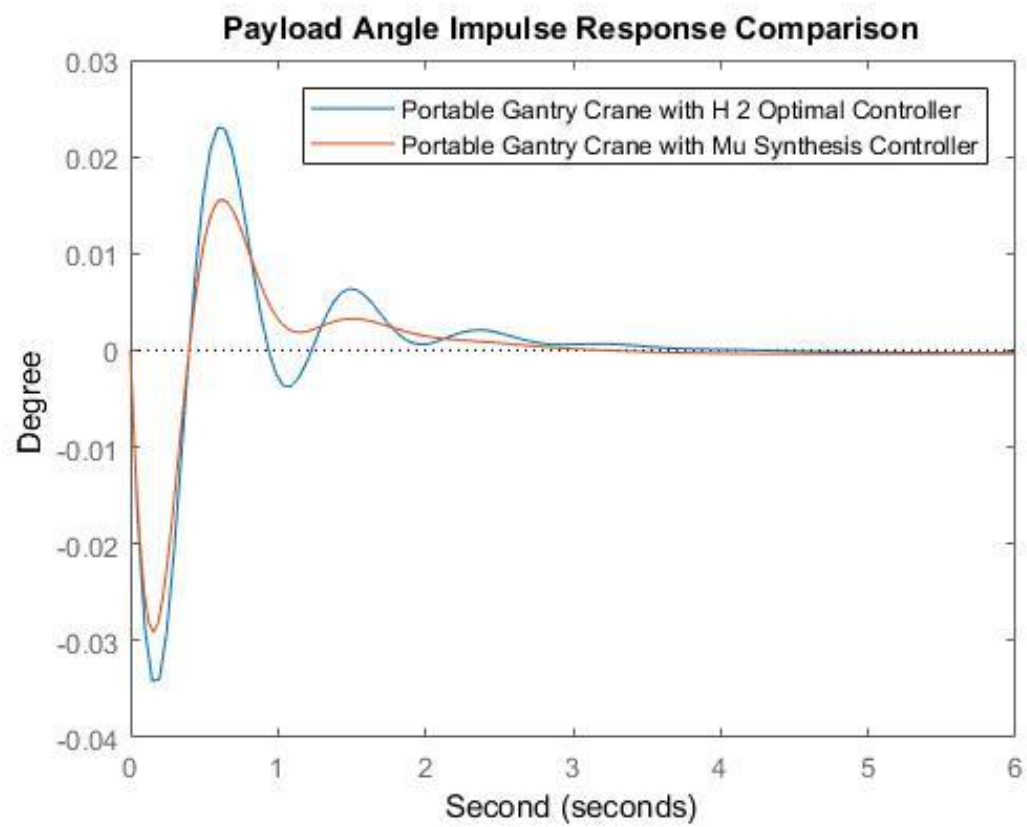

Figure 8 Comparison simulation result of the impulse response of the payload angle 
The impulse response comparison simulation result shows that the portable gantry crane with $\mu$ synthesis controller improves the payload and trolley vibration (overshoot) and settling time.

\subsection{Comparison of the Portable Gantry Crane with the Proposed Controllers for a Step Force Signal}

The comparison simulation result of the step response of the trolley position and payload angle for a 100N input force are shown in Figure 9 and Figure 10 respectively.

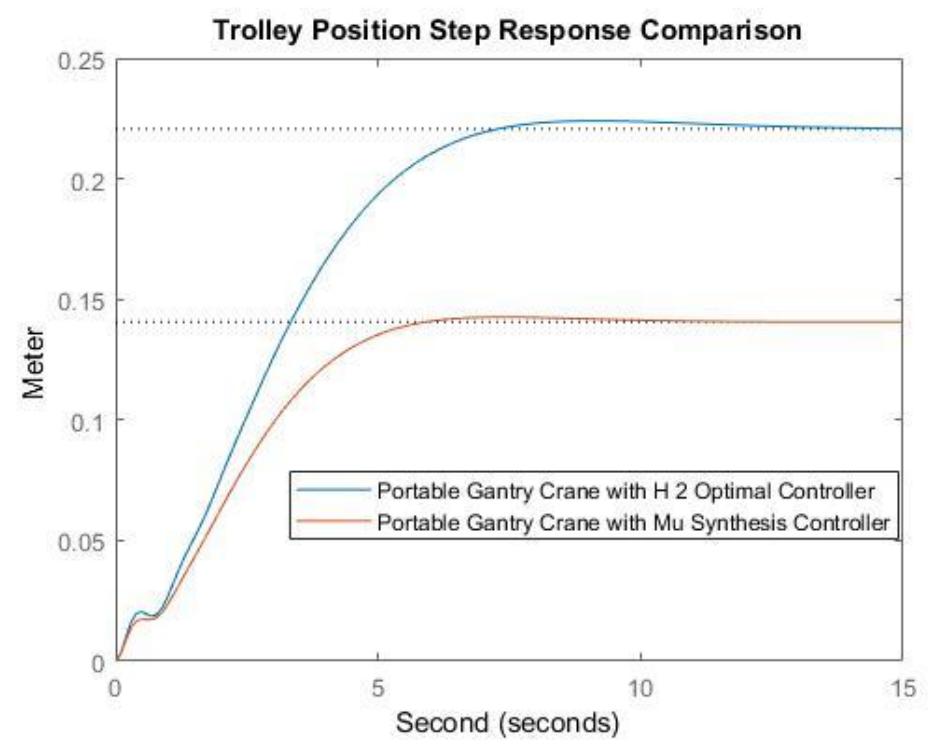

Figure 9 Comparison simulation result of the step response of the trolley position

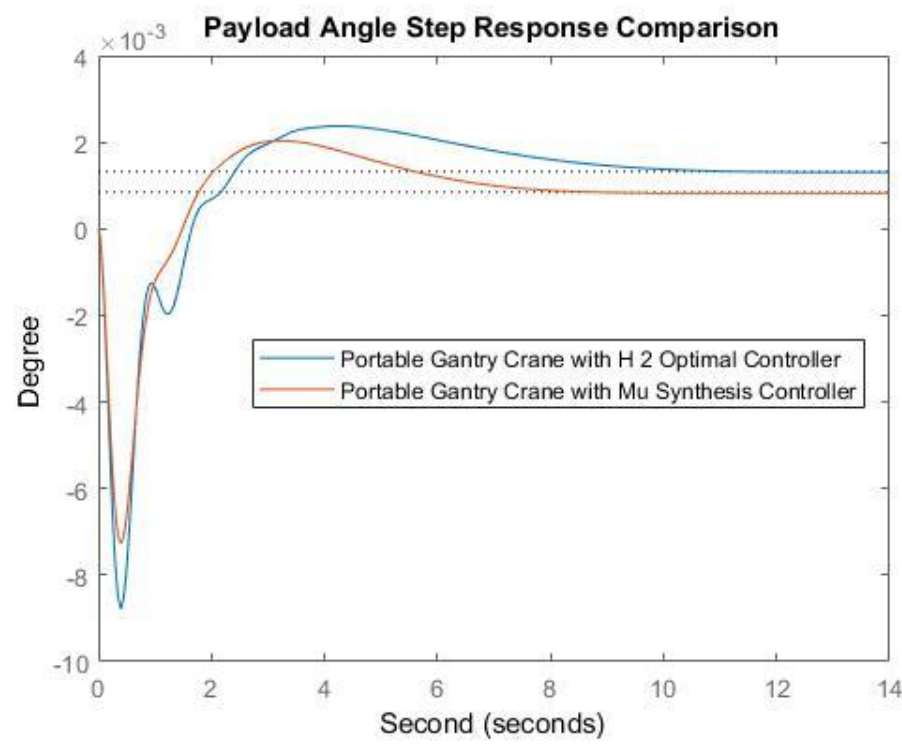

Figure 10 comparison simulation result of the step response of the payload angle 
The step response comparison simulation result shows that the portable gantry crane with $\mu$ synthesis controller improves the trolley vibration and minimized the payload angle.

\section{Conclusion}

In this paper, modeling, designing and controlling of a portable gantry crane have been done considering trolley vibration effect on payload angle limitation. The open loop system shows that the system is not stable therefore a robust control technique have been used. H 2 and $\mu$ - synthesis controllers are designed for the system and simulation test has been done for a step and impulse force input signal. Both of the simulation results proves the effectiveness of the proposed $\mu$ synthesis controller for improving the payload angle limitation with the presence of trolley position disturbance.

\section{Reference}

[1].Peng Guo et al. "Logic Based Benders Decomposition for Gantry Crane Scheduling with Transferring Position Constraints in a Rail Road Container Terminal" Journal of Engineering Optimization, Vol. 12, No. 1, 2020.

[2]. Tung Lam Nguyen et al. "Vibration Suppression Control of a Flexible Gantry Crane System with Varying Rope Length" Journal of Control Science and Engineering, Vol. 2019, Article ID 9640814, 8 pages, 2019.

[3]. Nguyen H. H et al. "Nonlinear Control of a Gantry Crane System with Limited Payload Angle" International Journal of Electrical and Electronics Engineering, Vol. 5, Issue 8, 2018.

[4]. Tian Luo et al. "Optimization of Gantry Crane Scheduling in Container Sea Rail Intermodal Transport Yard” Mathematical Problems in Engineering, Vol. 2018, Article ID 9585294, 11 pages, 2018.

[5].Peng Guo et al. "Gantry Crane Scheduling in Intermodal Rail Road Container Terminals" International Journal of Production Research, Vol. 56, Issue 16, 2018.

[6].T.L. Nguyen et al. "Nonlinear Control of Flexible Two Dimentional Overhead Cranes" Adaptive Robust Control Systems, 2018.

[7]. Katarina M. et al. "Static Analysis of Gantry Crane-Preliminary Study" DEStech Transactions on Engineering and Technology Research, Vol. 12, No. 2, 2016. 